\title{
Carbonyl Derivatives of Gold and Related Organometallics
}

\author{
Daniela Belli Dell' Amico and Fausto Calderazzo \\ Dipartimento di Chimica e Chimica Industriale, Università di Pisa, \\ Via Risorgimento 35, I- 56126 Pisa, Italy
}

\begin{abstract}
The properties and reactions of simple gold carbonyls and related compounds are described and the bonding within the gold carbonyl molecules discussed in terms of bond dissociation enthalpies.
\end{abstract}

Although the organometallic chemistry of gold is still rather limited (but see accompanying article in this issue of Gold Bulletin by R V Parish (1)) it presents aspects of uniqueness. Some of the properties of gold organometallics may be understood if in the oxidation state I, as is the case in some of the complexes described in this review, the electronic configuration of gold is $5 \mathrm{~d}^{10}$. This means that we are dealing with a non-transition system characterized by a closed-shell configuration, expected to be colourless and diamagnetic.

When carbon-based ligands are considered, we can distinguish one-electron donors (alkyls, aryls; ie hydrocarbyls) and two-electron donors. Excellent reviews have appeared $(2 \mathrm{a}, \mathrm{b})$ concerning hydrocarbyl derivatives of gold(I) and gold(III), including structural aspects (2c) and this subject will not be treated here. We limit the presentation to gold organometallics with two-electron donor carbon-based ligands, namely carbon monoxide, olefins, isonitriles and cyanides.

Generally, within transition metals, bond dissociation enthalpies (BDE) of metal-carbonyl bonds can be discussed in conjunction with metal-methyl bonds (3). For example, for some typical $5 \mathrm{~d}$ elements such as tungsten or rhenium, BDE's have been evaluated to be $\left(\mathrm{kJ} \mathrm{mol}^{-1}\right)$ : W-Me, $160 \pm 6$ (average in $\mathrm{WMe}_{6}$ ); W-CO, $178 \pm 1$ (average in hexacarbonyltungsten(0)); Re-Me, 220 11 , in $\mathrm{ReMe}(\mathrm{CO})_{5}$; Re-CO, $187 \pm 6$ (average in $\operatorname{Re}_{2}(\mathrm{CO})_{10}$ ). If extrapolation to gold is allowed, something similar would be expected to occur, unless additional factors come into play. It is therefore interesting to see whether or not these expectations are met. The synthesis of the gold organometallics described to date provides some relevant information.

The carbonyl derivatives of gold(I) reported in the literature all have ligands of high electronegativity or ligands containing electron-withdrawing substituents and it is interesting to note the carbonyl vibrational frequencies in the infrared spectra of the following mononuclear, dinuclear and cationic species: $\mathrm{AuCl}(\mathrm{CO})$ which has $\nu_{\mathrm{co}}=2162 \mathrm{~cm}^{-1}$ (4); $\mathrm{AuBr}(\mathrm{CO}), v_{\mathrm{co}}=2159 \mathrm{~cm}^{-1}(4) ; \mathrm{Cl}_{3} \mathrm{Au}(\mu-\mathrm{Cl}) \mathrm{Au}(\mathrm{CO})$, $v_{\mathrm{co}}=2180 \mathrm{~cm}^{-1}(5) ; \mathrm{Au}\left(\mathrm{SO}_{3} \mathrm{~F}\right)(\mathrm{CO}), v_{\mathrm{co}}=2195 \mathrm{~cm}^{-1}$ (6); a fluorinated tris(pyrazolyl)borato complex, $\left[\mathrm{HB}\left(3,5-\left(\mathrm{CF}_{3}\right)_{2} \mathrm{C}_{3} \mathrm{HN}_{2}\right)_{3}\right] \mathrm{Au}(\mathrm{CO}), v_{\text {co }}=2144 \mathrm{~cm}^{-1}$ (7); $\left[\mathrm{Au}(\mathrm{CO})_{2}\right]\left[\mathrm{UF}_{6}\right], \quad \nu_{\mathrm{co}}=2200 \mathrm{~cm}^{-1}$ (8) or $\left[\mathrm{Au}(\mathrm{CO})_{2}\right]\left[\mathrm{Sb}_{2} \mathrm{~F}_{11}\right], v_{\mathrm{co}}=2217 \mathrm{~cm}^{-1}$ (9). All these compounds have high $\nu_{\mathrm{co}}$ 's, sometimes well above that of uncoordinated carbon monoxide which is $2147 \mathrm{~cm}^{-1}$ (10), thus suggesting little or no $\pi$-back donation within the Au-CO bond (11), and we should therefore think of these compounds in terms of the ' $\sigma$-bonding only' model typical of the interaction of $\mathrm{CO}$ with a metal of $d^{10}$ electron configuration.

\section{SYNTHESIS}

The synthesis of the chloro- derivative of gold(I), $\mathrm{AuCl}(\mathrm{CO})$, has been studied in detail. In thionyl chloride as medium, the reaction of anhydrous gold(III) chloride with $\mathrm{CO}$ gives excellent yields, via the dinuclear $\mathrm{Cl}_{3} \mathrm{Au}(\mu-\mathrm{Cl}) \mathrm{Au}(\mathrm{CO})$ and the mixedvalence gold(I)-gold(III) chloride $\mathrm{Au}_{4} \mathrm{Cl}_{8}$ intermediates (12); with carbonyl chloride, $\mathrm{COCl}_{2}$, being the 
oxidation product. The thermodynamics of the reaction involving the formation of carbonyl chloride are so highly favoured $\left(\Delta \mathrm{G}^{0}{ }_{\mathrm{r}}\left(\mathrm{CO}_{(\mathrm{g})}+\mathrm{Cl}_{2(\mathrm{~g})} \rightarrow\right.\right.$ $\left.\mathrm{COCl}_{2(\mathrm{~g})}=-67.7 \mathrm{~kJ} \mathrm{~mol}^{-1}(13)\right)$, that any one of the three products can be obtained in high yields depending on the $\mathrm{CO}: \mathrm{Au}(\mathrm{III})$ molar ratio.

The preparation of the bromo-derivative, $\mathrm{AuBr}(\mathrm{CO})$, which is unstable in the solid state, is interesting (4). This bromo-carbonyl can be prepared by reductive carbonylation of gold(III) bromide:

$$
\begin{aligned}
& 1 / 2 \mathrm{Au}_{2} \mathrm{Br}_{6}+2 \mathrm{CO} \rightleftharpoons \mathrm{AuBr}(\mathrm{CO})+\mathrm{COBr}_{2} \\
& \mathrm{COBr}_{2} \rightleftharpoons \mathrm{CO}+\mathrm{Br}_{2} \\
& 1 / 2 \mathrm{Au}_{2} \mathrm{Br}_{6}+\mathrm{CO} \rightleftharpoons \mathrm{AuBr}(\mathrm{CO})+\mathrm{Br}_{2}
\end{aligned}
$$

In view of the now thermodynamically unfavourable reaction to carbonyl bromide $\left[\left[\Delta \mathrm{G}^{0}{ }_{\mathrm{r}}\right.\right.$ $\left.\left(\mathrm{CO}_{(\mathrm{g})}+\mathrm{Br}_{2(\mathrm{l})} \rightarrow \mathrm{COBr}_{2(\mathrm{~g})}\right)=+26.3 \mathrm{~kJ} \mathrm{~mol}^{-1}(13)\right], \mathrm{a}$ substantially quantitative conversion to the desired product is only obtained when bromine is removed by cyclohexene. $\mathrm{AuBr}(\mathrm{CO})$ can also be obtained by direct carbonylation of $\mathrm{AuBr}$.

The gold(I) halides, AuX, may be converted quantitatively to the halocarbonyl $\mathrm{AuX}(\mathrm{CO})$ by treatment with $\mathrm{CO}(4)$ :

$$
\mathrm{AuX}+\mathrm{CO} \longrightarrow \mathrm{AuX}(\mathrm{CO})(\mathrm{X}=\mathrm{Cl}, \mathrm{Br})
$$

The BDE relative to the $\mathrm{Au}(\mathrm{I})$-CO system can be readily calculated (17) to be at least $210 \mathrm{~kJ} \mathrm{~mol}^{-1}$ from some thermodynamic data available in the literature $(13)^{*}$, and this is in agreement with the results of a recent theoretical calculation (18).

Within the series of halide derivatives, the stability of carbonyls with respect to dissociation $(\mathrm{AuX}+\mathrm{CO})$ decreases in the sequence $\mathrm{Cl}>\mathrm{Br}>\mathrm{I}$ : in line with the combined effects of both $\mathrm{Au}-\mathrm{X}$ and Au-CO BDE's decreasing in the same sequence, if the main contribution to the $\mathrm{Au}-\mathrm{CO}$ bonding is of the $\sigma$-type.

Attempts to isolate carbonyl derivatives of gold(I)

\footnotetext{
* The BDE (at $298 \mathrm{~K}$ ) for the diatomic moleculc $\mathrm{Au}-\mathrm{Cl}, 343 \pm 9.6 \mathrm{~kJ} \mathrm{~mol}{ }^{-1}$, (see reference 13, Section 9) and the entropy change for the transfer of $\mathrm{CO}$ as diluted solution to a metal-bonded carbonyl group $\left(-145 \mathrm{~J} \mathrm{~K}^{-1}\right.$ mol-1, see reference 14), can be combined to give an estimated value of about $210 \mathrm{~kJ}$ mol $^{-1}$ for the Au-CO BDE, after considering the $\mathrm{Au}-\mathrm{Cl}_{\mathrm{b}} \mathrm{BDE}$ to be $25 \%$ less than the $\mathrm{Au}-\mathrm{Cl}, \mathrm{BDE}\left(\mathrm{Cl}_{1}\right.$, and $\mathrm{Cl}_{\text {t }}$ designate bridging and terminal chlorides, respecrively), ie in rerms of percentages, the same as that estimated for palladium(II) (15). The entropy loss due to the binding of $\mathrm{CO}$ to gold(I) is believed to be compensated by the fragmentation of the polynuclear chloride-bridged structure of solid $\mathrm{AuCl}$ (16).
}

with thiolato or hydrosulfido ligands, by metathetical reactions with $\mathrm{AuCl}(\mathrm{CO})$ have failed (19a): the products isolated were sulfido and chloro complexes of gold(I) and coordinated carbon monoxide was lost (19b). Also, both $\mathrm{K}\left[\mathrm{Au}(\mathrm{CN})_{2}\right]$ and $\mathrm{Au}(\mathrm{CN})$ are unreactive towards carbon monoxide (19a). In this connection, it is interesting that a cyano-isonitrile complex of gold(I) has been reported, being obtained by electrophilic attack on $\mathrm{K}\left[\mathrm{Au}(\mathrm{CN})_{2}\right]$ :

$$
\left[\mathrm{Au}(\mathrm{CN})_{2}\right]^{-}+\mathrm{MeI} \longrightarrow \mathrm{I}^{-}+\mathrm{Au}(\mathrm{CN})(\mathrm{CNMe})(3)
$$

This compound contains substantially linearly coordinated gold(I) (20), with $\mathrm{Au}-\mathrm{C}_{\mathrm{CN}}$ and $\mathrm{Au}-\mathrm{C}_{\mathrm{CNM}}$ bond distances of 2.01 and $1.98 \AA$ respectively, the angle at gold being $176^{\circ}$.

\section{SPECTROSCOPY AND BONDING}

The high $\boldsymbol{v}_{\mathrm{co}}$ 's, which are a common feature of gold(I) carbonyl derivatives, are increased still further in $\mathrm{AuCl}(\mathrm{CO})$ (by about $10 \mathrm{~cm}^{-1}$ ), when the solvent is changed from hydrocarbon to chlorohydrocarbon (4). Changes of this type have been observed with other carbonyl compounds $(17,21)$, and are suggestive of a specific weak solvent-solute interaction. The solid-state structure of $\mathrm{AuCl}(\mathrm{CO})$, as reported by Jones (22), indicates that the gold atom in this mononuclear compound is linearly coordinated with the chlorine and carbon atoms with $\mathrm{Au}-\mathrm{Cl}$ and $\mathrm{Au}-\mathrm{C}$ bond distances of $2.261(6)$ and $1.93(2) \AA$, respectively, the bond angle at gold being $180^{\circ}$ by symmetry. A reevaluation of the published data in terms of packing,

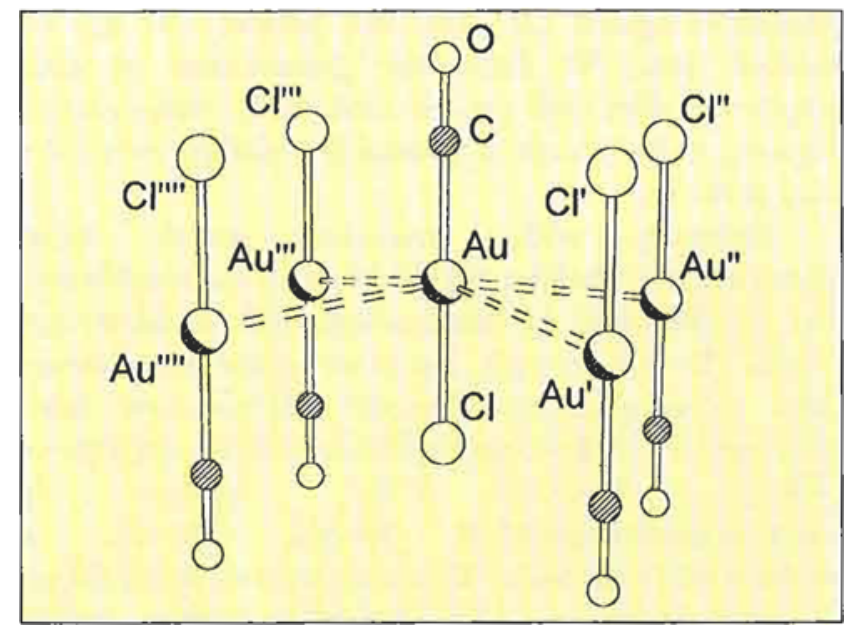

Figure Crystal packing of $A u C l(C O)$; recalculated from the data of Reference 22 . $^{\prime}=1 / 2-x, 1 / 2-y, 1-z_{;}{ }^{\prime \prime}=-1 / 2-x, 1 / 2-y$, $I-z ;{ }^{\prime \prime \prime}=-1 / 2-x, 1 / 2-y,-z ;{ }^{\prime \prime \prime}=1 / 2-x, 1 / 2-y,-z$. 
see Figure, indicates that the $\mathrm{C} \cdots \mathrm{Cl}$ intermolecular contacts of $3.352 \AA$ are in fact at least as important as the Au $\cdots$ Au contacts of $3.380 \AA$. The molecules appear to be packed in such a way as to minimize the $\mathrm{C} \cdots \mathrm{Cl}$ non-bonding distances: the deviation of the carbon atom from the best $\mathrm{Cl}^{\prime}-\mathrm{Cl}^{\prime \prime}-\mathrm{Cl}^{\prime \prime \prime}-\mathrm{Cl}^{\prime \prime \prime \prime}$ plane is $0.11 \AA$, while the deviation of the gold atom from the best $A u^{\prime}-A u^{\prime \prime}-A u^{\prime \prime \prime}-A u^{\prime \prime \prime \prime}$ plane is $0.450 \AA$. A similar situation has recently been encountered in the crystal packing of square-planar cis- $\mathrm{PtCl}_{2}(\mathrm{CO})_{2}$ (23), where the interplanar $\mathrm{C}$... Cl interactions were similarly found to be the most important ones.

\section{CARBON MONOXIDE $v$ S OLEFIN COORDINATION TO GOLD(I)}

Earlier work (24) had indicated that carbon monoxide is displaced by the cyclic olefin norbornene with a $\mathrm{K}$ of $4 \pm 1$ at $21.5^{\circ} \mathrm{C}$, corresponding to a $\Delta \mathrm{G}^{\circ}$ of the reaction of about $-3 \mathrm{~kJ} \mathrm{~mol}^{-1}$ and that bonding to the olefin is slightly favoured with respect to carbon monoxide.

$\mathrm{AuCl}(\mathrm{CO})+$ olefin $\Longrightarrow \mathrm{AuCl}($ olefin $)+\mathrm{CO}$

(olefin $=$ norbornene; solvent $=$ tetrachloroethane)

This result is at variance with those generally observed for typical transition metals, whereby olefin displacement by $\mathrm{CO}$ is highly favoured. It is interesting, in this connection, that the BDE's $\left(\mathrm{kJ} \mathrm{mol}^{-}\right.$ 1) for the gold(I) cation have been recently calculated (25a) to increase in the order : $\mathrm{H}_{2} \mathrm{O}(163.4)<\mathrm{CO}$ $(209)<\mathrm{NH}_{3}(289)<\mathrm{C}_{2} \mathrm{H}_{4}$ (306). On the other hand, the proton affinity increases from $\mathrm{CO}(25 \mathrm{~b})(587.1 \mathrm{~kJ}$ $\left.\mathrm{mol}^{-1}\right)$ to $\mathrm{C}_{2} \mathrm{H}_{4}\left(676.5 \mathrm{~kJ} \mathrm{~mol}^{-1}\right)$. This suggests again that for gold(I) the main contribution to the bonding of two-electron donor carbon-based ligands is $\sigma$ in character. The BDE of the gold(I)-methyl bond in AuMe has been recently calculated (26) to be $226 \mathrm{~kJ}$ $\mathrm{mol}^{-1}$, similar to the value estimated for the $\mathrm{Au}(\mathrm{I})-\mathrm{CO}$ bond.

\section{CONCLUSIONS}

Undoubtedly gold chemistry has some unusual features of great interest. Relativistic effects are responsible for $c a$ $20 \%$ contraction in the covalent radius of mercury ( 27 a-c) and, presumably, for a corresponding increase of the BDE . It has recently been observed (27d) that the radius of gold(I) is smaller than that of silver(I), based on the structural data for the isostructural $\left[\mathrm{M}\left(\mathrm{Pmes}_{3}\right)_{2}\right]^{+}$ cations, $\left(\mathrm{M}=\mathrm{Ag}, \mathrm{Au}\right.$; mes = 1,3,5- $\left.\mathrm{Me}_{3} \mathrm{C}_{6} \mathrm{H}_{2}\right)$ obtained from their tetrafluoroborate derivatives*.

Catalytic applications of gold are still rather small in number but are expected to grow in their importance. For example, gold(I) carbonyls formed by the reductive carbonylation of gold(III) chloride in zeolite cages have been found to be catalytically active in nitrogen oxide reduction by carbon monoxide (28a). Also $\mathrm{AuCl}(\mathrm{CO})$ was found to be the best catalyst for the thermal chlorination of carbon monoxide to carbonyl chloride in the absence of light (28b).

An example of homogeneous solution catalysis by gold has recently been described in Gold Bulletin (29), which has also published a discussion on the potential of gold in heterogeneous catalysis (30).

\section{ACKNOWLEDGEMENTS}

The authors are grateful to the Consiglio Nazionale delle Ricerche (CNR, Roma) and the Ministero dell' Università e della Ricerca Scientifica e Tecnologica for support of the work and to all their coworkers for their interest, ability and competence. Thanks are also due to Dr F Marchetti for the calculations of the solid-state structure of $\mathrm{AuCl}(\mathrm{CO})$.

\section{ABOUT THE AUTHORS}

Fausto Calderazzo is Professor of General and Inorganic Chemistry at the University of Pisa. After his degree in Chemistry from the University of Firenze, Italy, he has been involved in the study of organometallic and coordination compounds in their synthetic, mechanistic and thermodynamic aspects within the following research and educational institutions: Politecnico di Milano, Institute of Industrial Chemistry; Massachusetts Institute of Technology, Department of Chemistry; Cyanamid European Research Institute, Cologny, Geneva; Università di Pisa, Italy.

Daniela Belli Dell' Amico graduated from the University of Pisa in 1971 and she is presently Associate Professor of General and Inorganic Chemistry at the University of Pisa: her recent interests include organometallic chemistry of late transition metals and the synthesis and reactivity of N,N-dialkylcarbamato complexes of transition metals, including their use in the cation implantation on metal oxide surfaces.

* Sce W S Rapson, Gold Bull., 1996, 29, 143 


\section{REFERENCES}

1 R.V. Parish, Gold Bull., 1997, 30, 3

2a R.J. Puddephatt, 'Gold', in 'Comprehensive Organometallic Chemistry', G. Wilkinson, F.G.A.Stone and E. W. Abel, Eds., Vol. 2, Pergamon Press, Oxford-New York-TorontoSydney-Paris-Frankfurt, 1982, p.765

2b A. Grohmann and H. Schmidbaur, 'Gold', in 'Comprehensive Organometallic Chemistry', G. Wilkinson, F. G. A. Stone and E. W. Abel, Eds., J. L. Wardell, Vol. Ed., Vol. 3, Pergamon-Elsevier, 1995, p. 1

2c P.G. Jones, Gold Bull., 1981, 14, 102; 1981, 14, $159 ; 1983,16,114 ; 1986,19,46$

3 J.A. Martinho Samões and J.L. Beauchamp, Chem. Rev., 1990, 90, 629

4a W. Manchot and H. Gall, Chem. Ber., 1925, 58, 2175

$4 \mathrm{~b}$ M.S. Kharasch and H.S. Isbell, J. Am. Chem. Soc., 1930, 52, 2919

4c D. Belli Dell' Amico and F. Calderazzo, Gazz. Chim. Ital., 1973, 103, 1099

5 D. Belli Dell' Amico, F. Calderazzo, P. Robino and A. Segre, J. Chem. Soc., Dalton Trans., 1991, 3017

6 H. Willner and F. Aubke, Inorg. Chem., 1990, 29, 2195

7 H.V.R. Dias and W. Jin, Inorg. Chem., 1996, 35, 3687

8 M. Adelhelm, W. Bacher, E. G. Höhn and E. Jacob, Chem. Ber., 1991, 124, 1559

9 H. Willner, J. Schaebs, G. Hwang, F. Mistry, R. Jones, J. Trotter and F. Aubke, J. Am. Chem. Soc., $1992,114,8972$

10 G. Herzberg, Spectra of Diatomic Molecules, 2nd ed., D. Van Nostrand, New York, 1950

11 F. Calderazzo and D. Belli Dell' Amico, Pure Appl. Chem., 1986, 58, 561

12 D. Belli Dell' Amico, F. Calderazzo, F. Marchetti, S. Merlino and G. Perego, J. Chem. Soc., Chem. Commun., 1977, 31

13 CRC Handbook of Chemistry and Physics, D. R. Lide and H. P. R. Frederikse, Eds., CRC Press, Boca Raton-Ann Arbor-London-Tokyo, 75th ed., 1994-1995, Section 5

14a F. Calderazzo and F.A. Cotton, Inorg. Chem., $1962,1,30$

$14 \mathrm{~b}$ F. Calderazzo, G. Fachinetti and C. Floriani, $J$. Am. Chem. Soc., 1974, 96, 3695

15a H. Schäfer, U. Wiese, K. Rinke and K. Brendel,
Angew. Chem., 1967, 79, 244; Angew. Chem., Int. Ed. Engl., 1967, 6, 253

15b D. Belli Dell' Amico, F. Calderazzo, F. Marchetti and S. Ramello, Angew. Chem., 1996, 108, 1430; Angew. Chem., Int. Ed. Engl., 1996, 35, 1331

16a J. Strähle and K.-P. Lörcher, Z. Naturforsch., 1974, 29b, 266

$16 \mathrm{~b}$ E.M.W. Janssen, J.C.W. Folmer and G.A. Wiegers, J. Less-Common Metals, 1974, 38, 71

17 F. Calderazzo, J. Organometal. Chem., 1990, 400, 303

18 I. Antes, S. Dapprich, G. Frenking and P. Schwerdtfeger, Inorg. Chem., 1996, 35, 2089

19a N. Pasqualetti, unpublished results, University of Pisa, 1994

$19 b$ D. Belli Dell' Amico, F. Calderazzo, N. Pasqualetti, R. Hübener, C. Maichle-Mössmer and J. Strähle, J. Chem. Soc., Dalton Trans., 1995, 3917

20 S. Esperås, Acta Chem. Scand., 1976, A 30, 527

21 D.M. Adams, 'Metal-Ligand and Related Vibrations', Arnold, London, 1967, p.107

22 P.G. Jones, Z. Naturforsch., 1982, 37 B, 823

23 F. Bagnoli, D. Belli Dell' Amico, F. Calderazzo, U. Englert, F. Marchetti, G.E. Herberich, N. Pasqualetti and S. Ramello, J. Chem. Soc., Dalton Trans., 1996, 4317

24 D. Belli Dell' Amico, F. Calderazzo, R. Dantona, J. Strähle and H. Weiss, Organometallics, 1987, 6, 1207

25a D. Schröder, J. Hrusák, R.H. Hertwig, W. Koch, P. Schwerdtfeger and $H$. Schwarz, Organometallics, 1995, 14, 312

$25 b$ B.J. Smith and L. Radom, J. Am. Chem. Soc., $1993, \mathbf{1 1 5}, 4885$

26 I. Antes and G. Frenking, Organometallics, 1995, 14, 4263

27a K.S. Pitzer, Acc. Chem. Res., 1979, 12, 271

27b P. Pyykkö and J.P. Desclaux, Acc. Chern. Res., $1979,12,276$

27c P. Pyykkö, Chem. Rev., 1988, 88, 563

27d A. Bayler, A. Schier, G.A. Bowmaker and H. Schmidbaur, J. Am. Chem. Soc., 1996, 118, 7006

28a S. Qiu, R. Ohnishi and M. Ichikawa, J. Chem. Soc., Chem. Commun., 1992, 1425

28b F. Calderazzo and D. Belli Dell' Amico, Inorg. Chem., 1982, 21, 3639

29 S. Komiya, S. Takuo, Y. Usui, M. Hirano and A. Fukuoka, Gold Bull., 1996, 29, 131

30 G. Hutchings, Gold Bull., 1996, 29, 123 